\title{
RADIO FREQUENCY INTERFERENCE SURVEY OVER THE 1.0 - 10.4 GHz FREQUENCY RANGE AT THE GOLDSTONE - VENUS TRACKING STATION
}

\author{
S. GULKIS, E. T. OLSEN, M. J. KLEIN, E. B. JACKSON \\ Jet Propulsion Laboratory \\ California Institute of Technology \\ Pasadena, California 91109
}

\section{INTRODUCTION}

Plans are currently being made to carry out a comprehensive, all-sky search for radio signals of extraterrestrial origin. The survey will employ the Goldstone tracking station near Barstow, California, and other sites in the northern and southern hemispheres. The principal parameters of this survey are given in Table 1. In preparation for this search, we have constructed a radio spectrum surveillance system (RSSS), and made a series of measurements of the RFI environment at the Goldstone-Venus tracking station. We describe in this paper the receiving system used (Crow et al. 1985), and the results of a low-sensitivity survey performed during February 16-24, 1987.

\section{TABLE I ALL SKY SURVEY PARAMETERS}

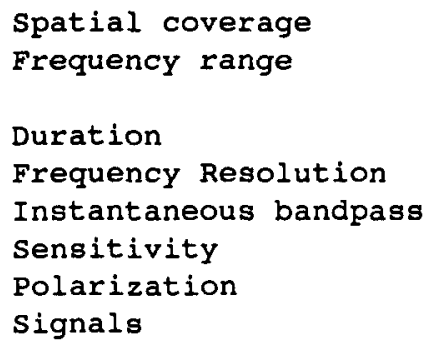

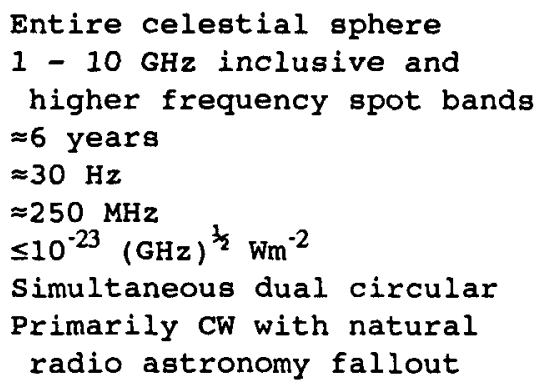

\section{THE RADIO SPECTRUM SURVEILLANCE SYSTEM}

The RSSS used for the present observations consisted of a log-period feed, a 1-m parabolic antenna, a set of $7 \mathrm{GaAsFET}$ amplifiers (followed by transistor amplifiers) covering the spectrum from $1.0-10.4 \mathrm{GHz}$, and a Tektronix 494P 
swept spectrum analyzer. A Tektronix 4052A digital computer/controller automatically controls the antenna azimuth, noise diode, amplifier section, spectrum analyzer, and dual-floppy disk recorder. The spectral data are processed in the $4052 \mathrm{~A}$ in near real time to determine whether a specified power threshold has been exceeded anywhere in the spectrum. The data describing such events are written on the floppy disks at the field station for further off-line analysis at JPL.

The antenna and amplifiers are mounted atop the roof of a mobile trailer van. The spectrum analyzer, computer, and recording equipment are mounted in a rack inside the van. For the observations reported here, the van was parked at the Goldstone-Venus tracking station (DSS 13), about 30 meters southwest of the main control building. In this location, the van is approximately $150 \mathrm{~m}$ east of the 26 meter antenna.

Data recorded on the floppy disks are taken to JPL and copied onto a hard disk of a VAX 750 computer for further analysis. A commercially available data base program, INGRES, is used to retrieve the data and custom software allows the investigator to perform parameter searches and generate various graphical displays.

\section{OBSERVATIONS}

The observations were carried out in a fully automated mode by prescheduling the controller to scan the spectrum analyzer from $1.0 \mathrm{GHz}$ to 10.4 $\mathrm{GHz}$ repeatedly at a resolution bandwidth of $10 \mathrm{KHz}$. The time required to complete a single scan was 40 minutes, and a total of 232 scans were made over the course of the survey. The antenna main beam was pointed in the direction of the zenith for these observations. In this orientation, the antenna is rather insensitive to radiation that arrives along the horizon. Assuming that the antenna gain in the direction of the horizon is the same as that from an omnidirectional antenna, the effective area for the survey is approximately $0.1 \mathrm{x}$ $\mathrm{L}^{2}$, where $\mathrm{L}$ is wavelength of the observation. The effective area for on-axis signals is approximately $0.5 \mathrm{~m}^{2}$. Power levels reported in this paper assume an omnidirectional antenna.

Each frequency was observed a total of 232 times, with nearly uniform coverage with time of day. Figure 1 shows the distribution of observations ("looks") with day of the week. Each day of the week is further divided into six 4hour intervals starting at midnight. The weekdays Monday and Tuesday were observed most frequently, whereas Sunday was observed least frequently. Only the first 4-hour interval (midnight to 4:00 A.M.) was observed on Sunday. A system noised temperature calibration was automatically performed daily between 3:00 A.M. and 4:00 A.M. local time. Table II gives the parameters used in the survey.

\section{TABLE II SURVEY \# 1 PARAMETERS}

$\begin{array}{ll}\text { Start date } & \text { February 16, } 1987 \\ \text { Stop date } & \text { February 24, } 1987 \\ \text { Number of sweeps } & 232\end{array}$




Antenna orientation
Frequency range
Resolution
Time constant
Baseline level
Threshold

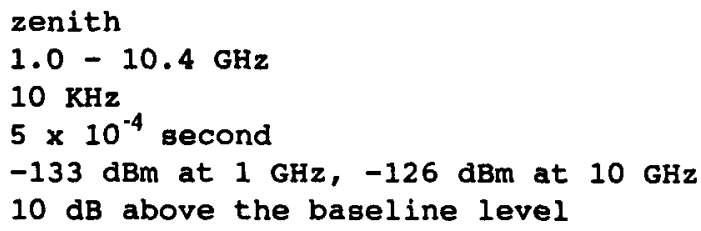

\section{RESULTS}

A total of 37,589 events were detected in the survey. Figure 2 shows a histogram of the number of events exceeding the threshold as a function of received power level. It is noted that the power levels for some interfering signals exceeded $-90 \mathrm{dBm}$. These signals were traceable to local microwave transmitters. The apparently low number of signal reported near the threshold level, approximately $-123 \mathrm{dBm}$, is believed to be due to the fact that the sensitivity of the survey varied by approximately $7 \mathrm{~dB}$ across the band due to differences in the receiver noise temperatures. We do not conclude that weaker signals are less prevalent than stronger signals. Figure 3 shows the cumulative distribution of hits as a function of a minimum received power level.

Figure 4 shows the probability of a signal exceeding the threshold as a function of frequency over the full frequency range of the survey, $1.0-10.4 \mathrm{GHz}$. The frequency resolution of the graph is approximately $10 \mathrm{MHz}$. This figure reveals that the probability is very nonuniform across the survey frequency range. The highest incidence of interference is in two frequency ranges: $1-3 \mathrm{GHz}$ and $7.7-8.3 \mathrm{GHz}$. Figure 5 shows an enlargement of Figure 4 in the frequency range $1.0-2.0 \mathrm{GHz}$. The frequency resolution of Figure 5 is approximately $1 \mathrm{MHz}$. It can be seen from this figure that the "Water Hold" frequency range, 1.4 - 1.7 $\mathrm{GHz}$, contains a significant amount of interference, but that the radio astronomy bands near $1.4 \mathrm{GHz}$ and $1.6 \mathrm{GHz}$ are relatively quiet, at least at the sensitivity achieved by this survey.

Figure 6 displays the probability of RFI events over the full $1.0-10.4 \mathrm{GHz}$ range as a function of day of week. As in Figure 1, each day is divided into six 4hour intervals. For this figure, the sample probability scale has been extended to less than zero so as to allow the possibility of distinguishing between zero sample probability and those intervals in which no observations were made. For example, the first 4-hour interval $(0 \mathrm{Hr}-4 \mathrm{Hr})$ on Monday and the last five 4hour intervals $(4 \mathrm{Hr}-24 \mathrm{Hr}$ ) on Sunday were not observed. This figure illustrates the pervasive nature of the interference. Interference was observed every day of the week, with little change in probability of occurrence with time of day.

Table III provides a list of the frequencies that have exhibited an interfering signal at least $10 \%$ of the time they were observed. A quick and dirty worst-case estimate of the fraction of the observed band which is obscured by RFI at least $10 \%$ of the time can be made by adding up all the frequency ranges in Table 3. This yields $7.21 \mathrm{MHz}$ out of $9.4 \mathrm{GHz}$, or approximately $7.7 \%$ of the band. 
TABLE III Frequencies with Probability of Interference $\geq 10 \%$

$\begin{array}{cccc}\text { Center Freq. } & \text { Probability } & \text { RF Range } & \text { Band } \\ \text { of RFI (MHz) } & \text { of RFI } & \text { Affected } & \text { Allocation* }\end{array}$

$\begin{array}{lccll}1000.015 & 0.6 & <10 \mathrm{KHz} \text { wide } & \text { AN } \\ 1051.685 & 0.4 & <10 \mathrm{KHz} \text { wide } & \text { AN } \\ 1085.420 & 0.5 & 1085.40 \mathrm{MHz}-1085.44 \mathrm{MHz} & \text { AN } \\ 1134.600 & 0.1 & <10 \mathrm{KHz} \text { wide } & \text { AN } \\ 1165.975 & 0.6 & 1165.94 \mathrm{MHz}-1166.11 \mathrm{MHz} & \text { AN } \\ 1302.515 & 0.4 & 1302.50 \mathrm{MHz}-1302.53 \mathrm{MHz} & \text { A } \\ 1310.850 & 1.0 & <10 \mathrm{KHz} \text { wide } & \text { AN } \\ 1723.410 & 0.2 & <10 \mathrm{KHz} \text { wide } & \text { F\&M } \\ 1723.525 & 0.6 & <10 \mathrm{KHz} \text { wide } & \text { F\&M } \\ 1723.640 & 0.2 & <10 \mathrm{KHz} \text { wide } & \text { F\&M } \\ 1724.525 & 1.0 & 1724.50 \mathrm{MHz}-1724.55 \mathrm{MHz} & \text { F\&M } \\ 1905.020 & 0.6 & <10 \mathrm{KHz} \text { wide } & \text { F\&M } \\ 2000.030 & 0.1 & <10 \mathrm{KHz} \text { wide } & \text { F\&M } \\ 2110.850 & 0.1 & <10 \mathrm{KHz} \text { wide } & \text { AF\&M } \\ 2112.420 & 0.2 & <10 \mathrm{KHz} \text { wide } & \text { F\&M } \\ 2115.225 & 1.0 & <10 \mathrm{KHz} \text { wide } & \text { F\&M } \\ 2605.020 & 0.5 & <10 \mathrm{KHz} \text { wide } & \text { BS } \\ 7786.785 & 0.9 & 7784.39 \mathrm{MHz}-7789.18 \mathrm{MHz} & \text { F } \\ 7832.015 & 0.2 & <10 \mathrm{KHz} \text { wide } & & \text { F } \\ 7879.970 & 0.5 & 7879.95 \mathrm{MHz}-7879.99 \mathrm{MHz} & \text { F } \\ 7884.960 & 0.7 & 7884.93 \mathrm{MHz}-7884.99 \mathrm{MHz} & \text { F } \\ 7889.970 & 0.3 & 7889.96 \mathrm{MHz}-7889.98 \mathrm{MHz} & \text { F } \\ 7934.430 & 0.3 & 7934.15 \mathrm{MHz}-7934.71 \mathrm{MHz} & \text { F\&MS } \\ 7934.960 & 0.3 & 7934.89 \mathrm{MHz}-7935.03 \mathrm{MHz} & \text { F\&MS } \\ 7935.110 & 0.1 & <10 \mathrm{KHz} \text { wide } & \text { F\&MS } \\ 7935.355 & 0.4 & 7935.25 \mathrm{MHz}-7935.46 \mathrm{MHz} & \text { F\&MS } \\ 7935.770 & 0.2 & 7935.69 \mathrm{MHz}-7935.85 \mathrm{MHz} & \text { F\&MS } \\ 8080.050 & 0.8 & 8079.73 \mathrm{MHz}-8080.37 \mathrm{MHz} & \text { F\&MS } \\ 8179.910 & 1.0 & 8179.88 \mathrm{MHz}-8179.94 \mathrm{MHz} & \text { F\&MS } \\ 8260.095 & 0.4 & 8260.06 \mathrm{MHz}-8260.13 \mathrm{MHz} & \text { F\&MS } \\ 8359.910 & 0.5 & 8359.89 \mathrm{MHz}-8359.93 \mathrm{MHz} & \text { F\&MS }\end{array}$

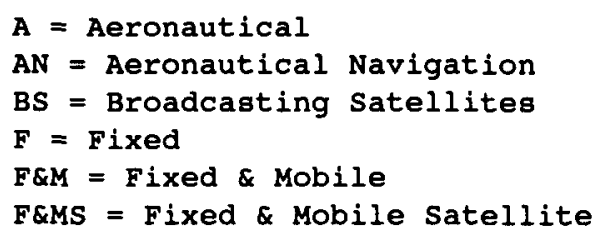


A more careful analysis of the data which includes an extrapolation to greater sensitivity is given in Figure 7. Here is shown the percent of the observed band which was obscured by RFI $\geq 10 \%$ of the time as a function of a limiting received power. The four points spanning the range from $-100 \mathrm{dBm}$ to $-116 \mathrm{dBm}$ are derived from the survey. Since the sidelobe sensitivity level at which SETI will be operating is closer to $-170 \mathrm{dBm}$, it is of great interest to determine the shape of this curve at lower power levels. A smooth curve has been drawn through the observed data in Figure 7 and extended to the power levels of interest to SETI. If the extrapolation is valid, we expect that perhaps $20 \%$ of the RF band between $1 \mathrm{GHz}$ and $10 \mathrm{GHz}$ will be obscured by RFT at the received power levels at which SETI will operate for signals coming in the sidelobes. We emphasize that this extrapolation extends the power level by more than $50 \mathrm{dBm}$ and is highly uncertain.

\section{CONCLUSIONS}

We conclude from this survey that most RFI in the $1-10 \mathrm{GHz}$ band occurs in relatively few bands. Nearly $1 \%$ of the entire band shows interference at the $-116 \mathrm{dBm}$ level or stronger with a probability of occurrence $\geq 10 \%$. The interfering signals from satellites will probably show up at power levels significantly less than were achieved in this survey. Surveys at approximately 30 $\mathrm{dB}$ greater sensitivity can be achieved with the current RSSS in a reasonable time through (1) use of a discone antenna to provide higher sensitivity along the horizon, and (2) by observing with a more narrow bandwidth. Surveys at even greater sensitivity, approaching those achieved by SETI in the sidelobes, must await more sensitive systems.

\section{ACKNOWLEDGEMENT}

The research described in this paper was performed by the Jet Propulsion Laboratory, California Institute of Technology, under contract with the National Aeronautics and Space Administration.

\section{REFERENCES}

Crow, B., Lokshin, A., Marina, M. and Ching, L. "SETI Radio Surveillance System, JPL Publication - TDA Progress Report 42-82, April-June 1985, pp. 173-184. 


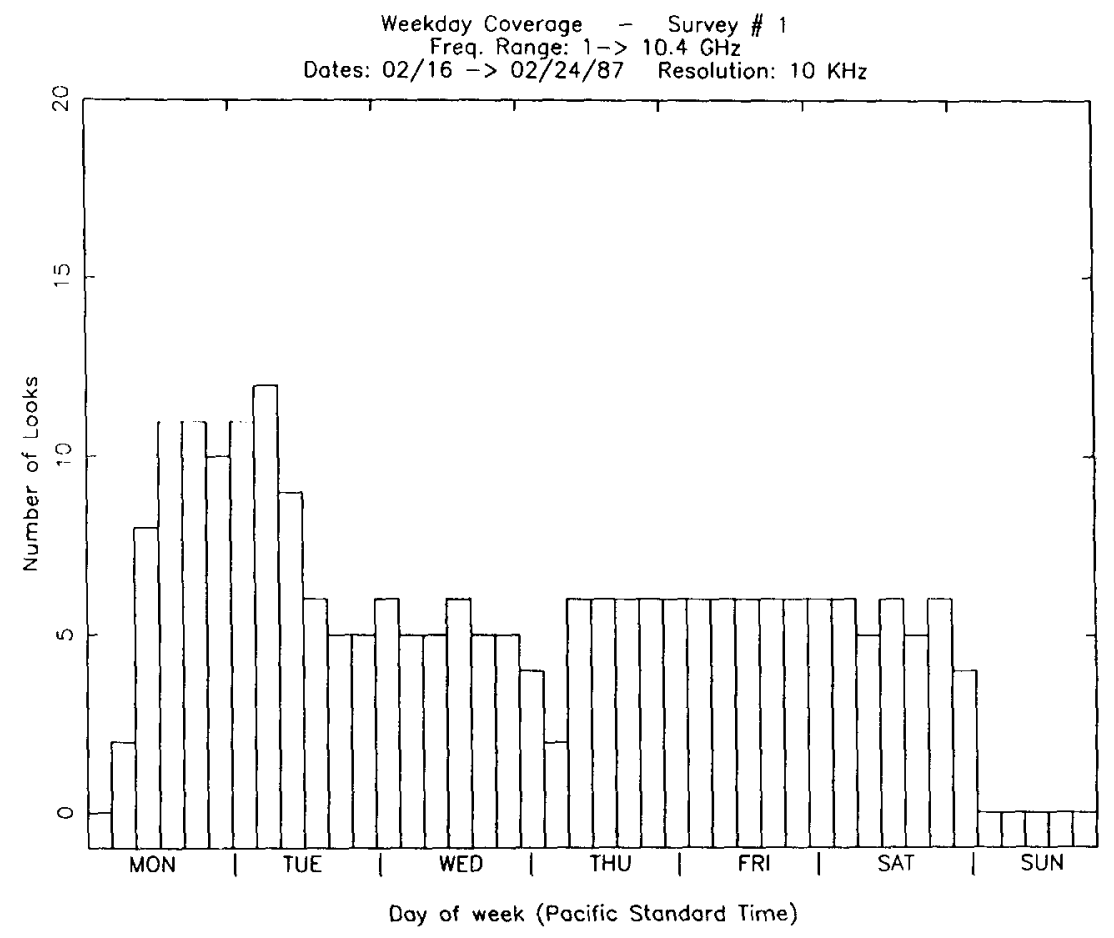

Figure 1 - Number of looks versus day of week for Survey \#1, 1.0 - 10.4 GHz 


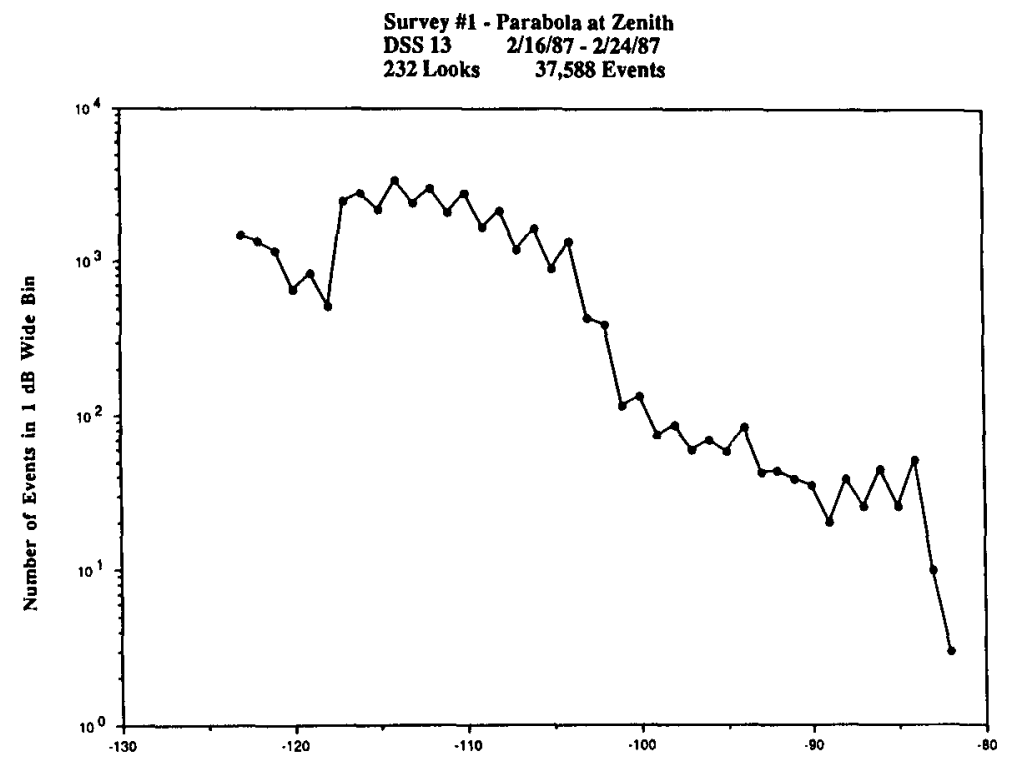

Power (Bin Center) (dBm)

Figure 2 - Histogram of number of RFI events as a function of received power for Survey \#1, 1.0 - $10.4 \mathrm{GHz}$ 


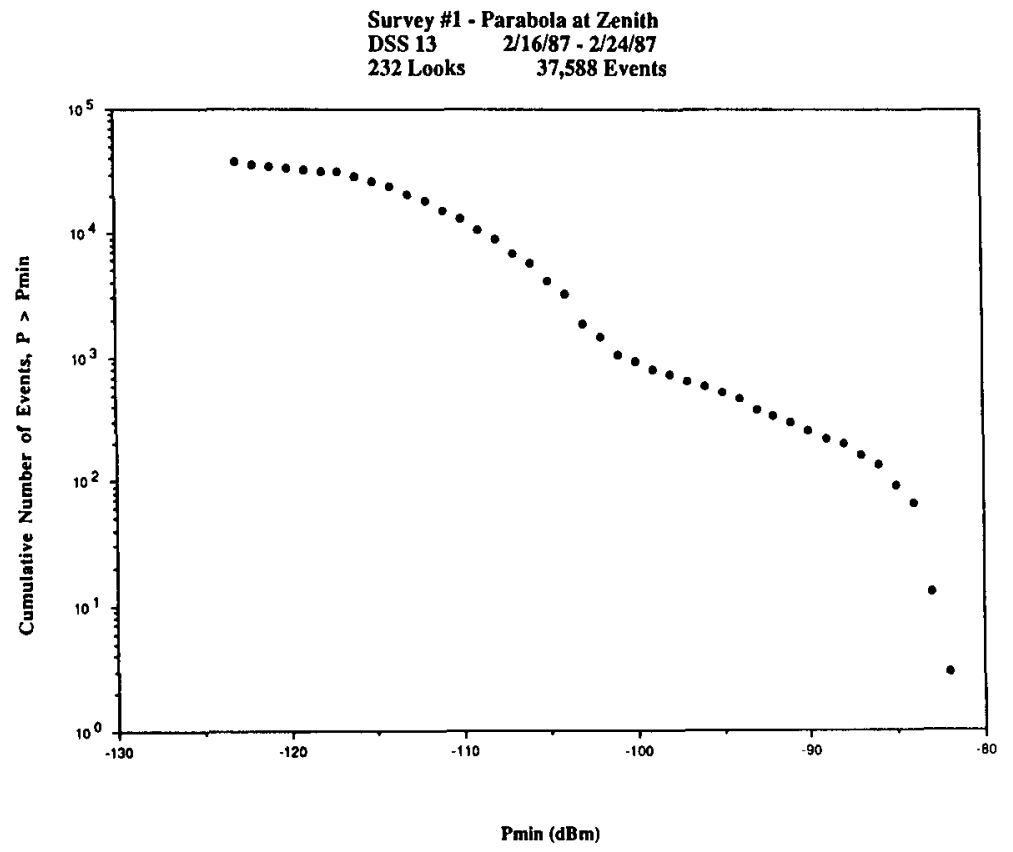

Figure 3 - Cumulative Histogram of number of RFI events as function of $P_{\min }$ for Survey \#1, $1.0-10.4 \mathrm{GHz}$ 


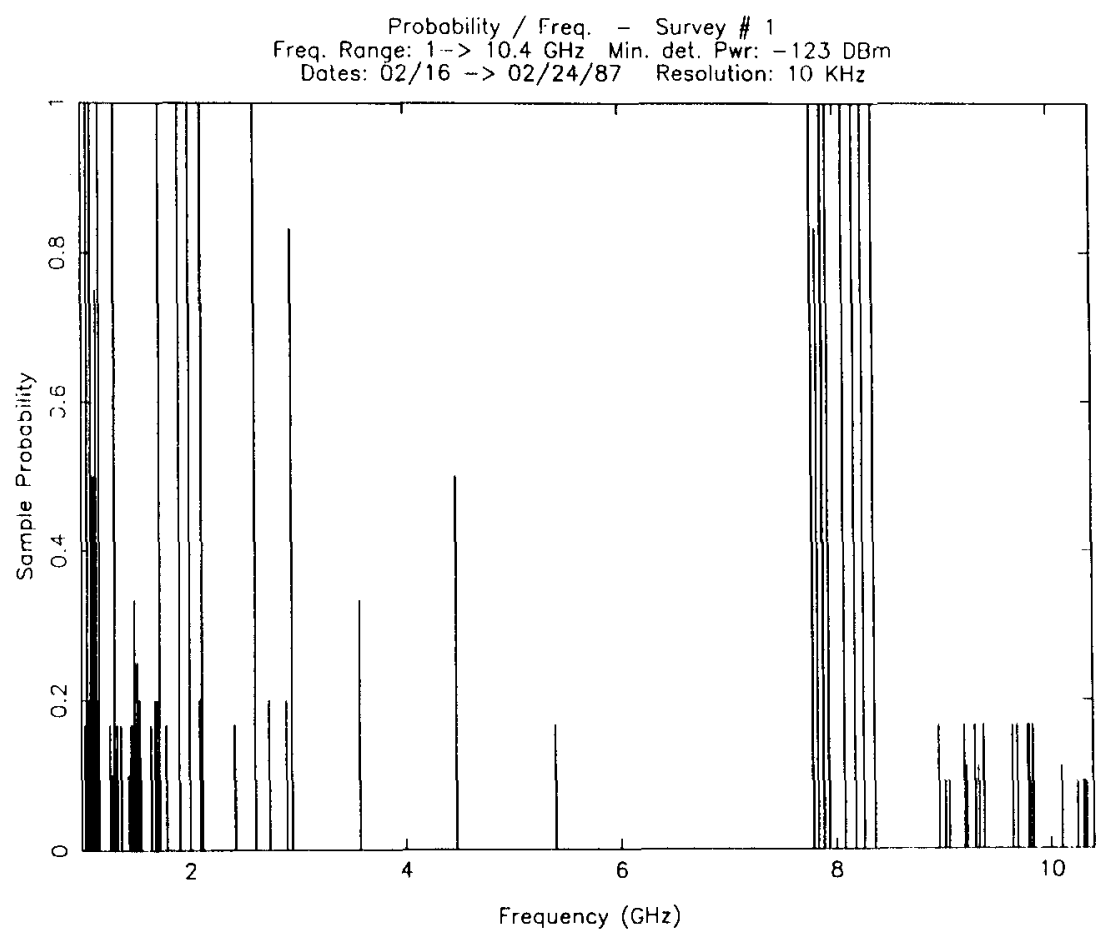

Figure 4 - Probability of RFI events as a function of frequency for Survey \#1, $1.0-10.4 \mathrm{GHz}$ 


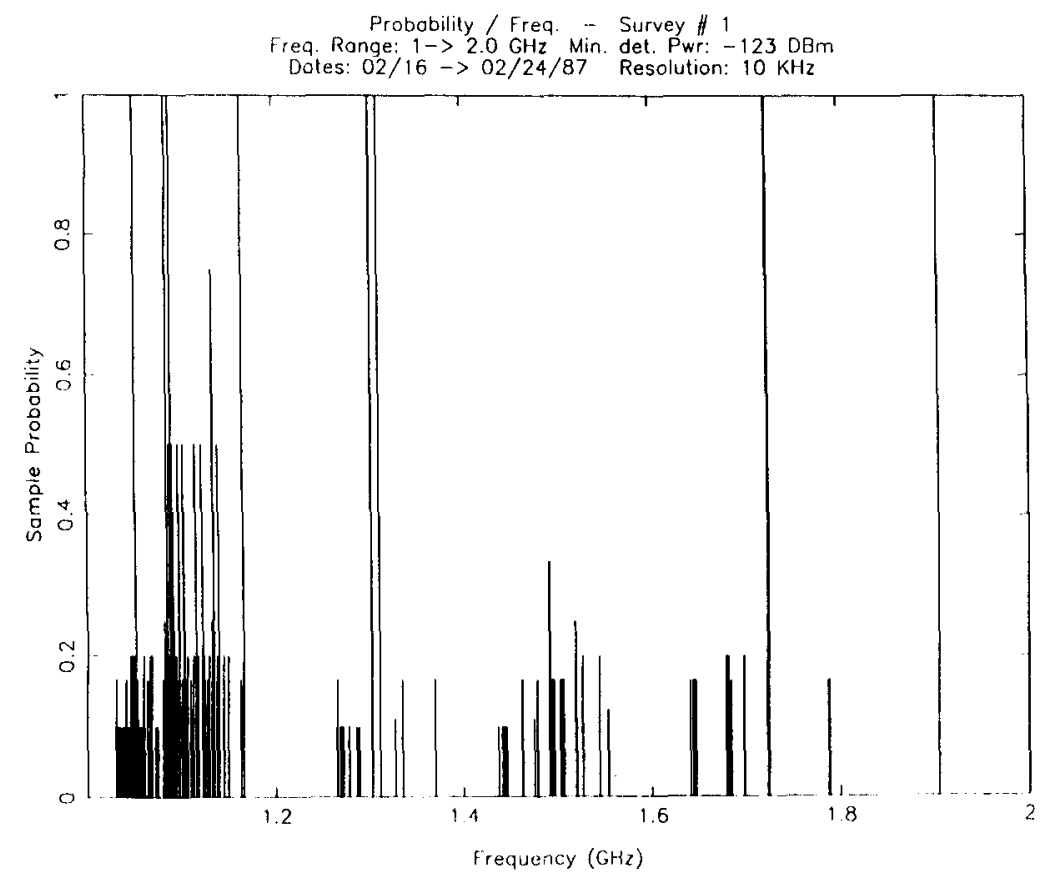

Figure 5 - Probability of RFI events as a function of frequency for Survey \#1, $1.0-2.0 \mathrm{GHz}$ 


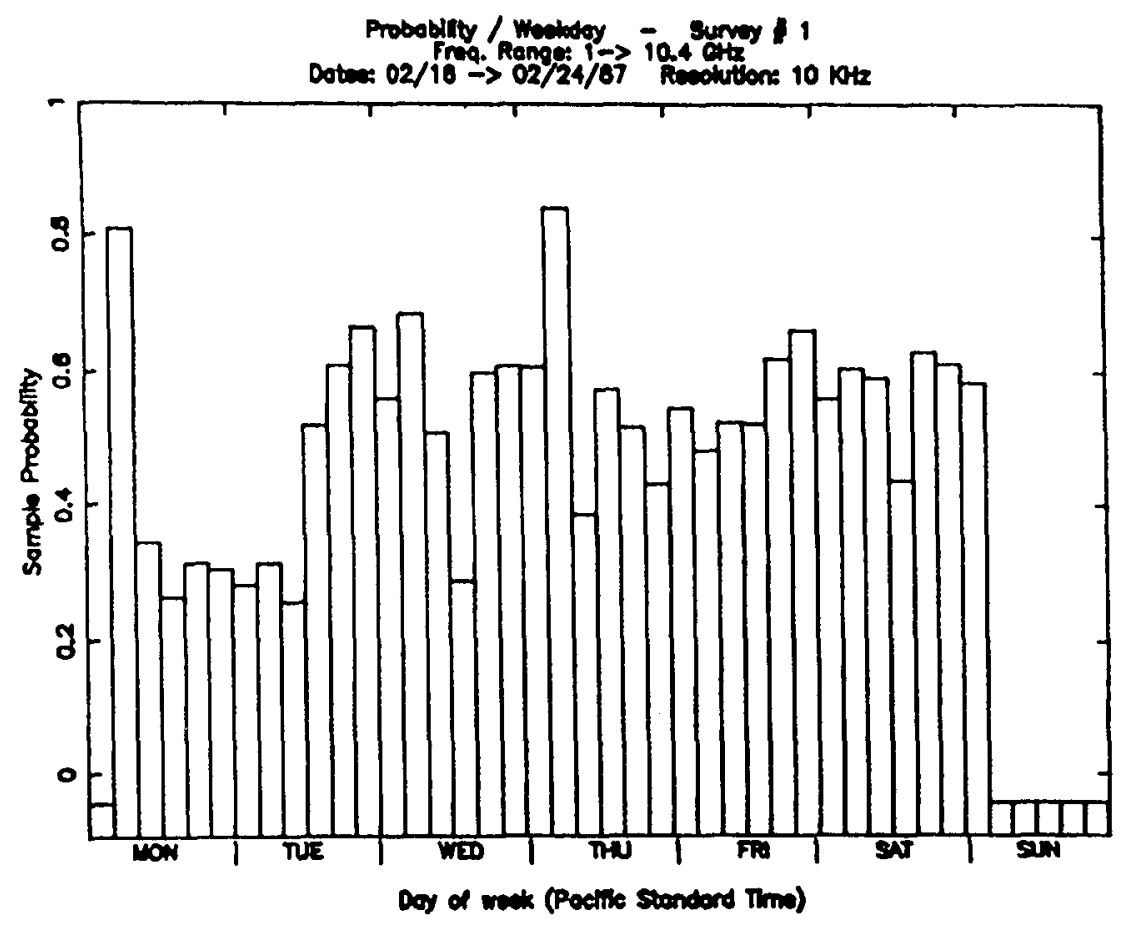

Figure 6 - Probability of RFI events as a function of 4 hour slice of day of week, for Survey \#1, $1.0-10.4 \mathrm{GHz}$ 


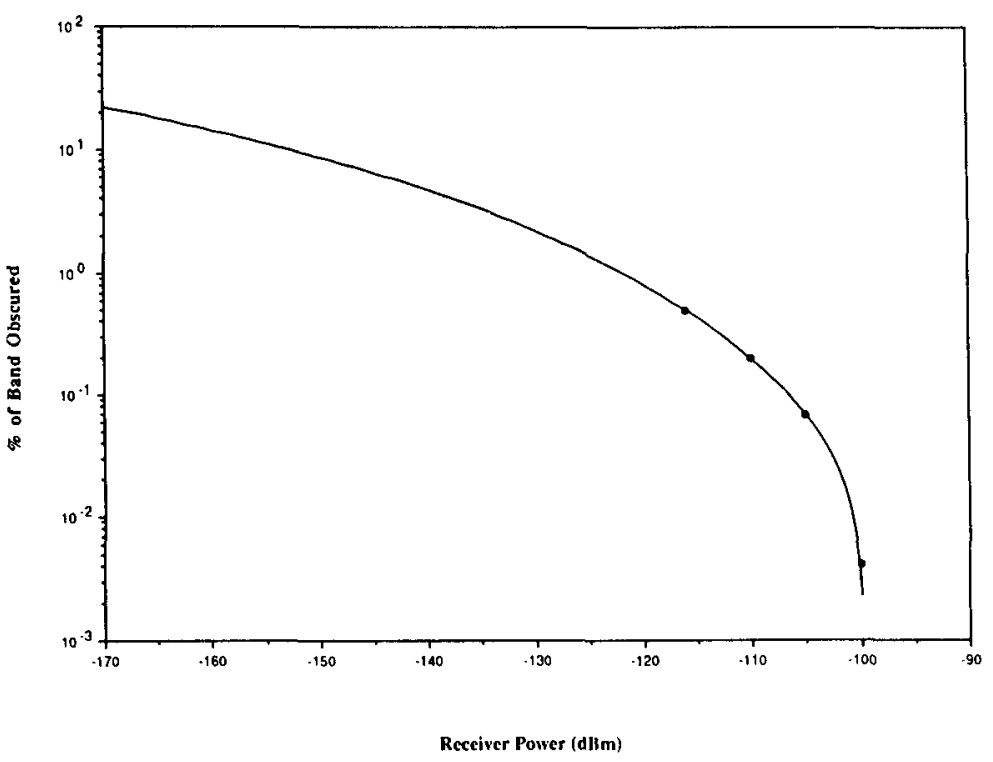

Figure 7 - Observed and extrapolated percent of bandpass obscured by RFI events with probability greater than $10 \%, 1.0-10.4 \mathrm{GHz}$ 